\title{
Packet Switching Network in Throughput Rate Less Code
}

\author{
G. Michael, R.Kavitha, Allin Geo Varghese
}

\begin{abstract}
We consider show movement and a discrete-time lining model, where the quantities of bundle landings over various timeslots are autonomous and indistinguishably disseminated and the parcel length is an altered worth. The transmission begins when there are more than bundles holding up in the approaching line proposed for every one of the collectors. The telecast stations are displayed by Markov balanced bundle eradication stations, where the parcel can either be deleted or effectively gotten and for every beneficiary the present station state circulation relies on upon the station states in past parcel transmissions. Gilbert-Elliott deletion channels, we can give a lower bound on the greatest achievable throughput
\end{abstract}

Keywords: Markov Models, Sensor Systems

\section{INTRODUCTION}

Sensor systems are differentiated as apart of various application areas, for example, digital physical framework frameworks, ecological checking, power matrices, and so on. Information are created at an expansive number of sensor hub sources and prepared in-system at middle bounces on their way to a base station (BS) that performs basic leadership. In a multi-jump sensor system [1], information provenance permits the BS to follow the source and sending way of an individual information parcel. Provenance must be recorded for every parcel, except imperative obstacles emerges because of the tight stockpiling, vitality and data transferring of data capacity limitations of sensor hubs. It is important to address security necessities, for example, classification, honesty and freshness of provenance. We will likely outline a provenance encoding and interpreting component that fulfills such security and execution needs.[10,11,12,13]

\section{RELATED WORK}

Revised Manuscript Received on July 22, 2019.

Dr.G.Michael, Department of Computer Science and Engineering, Bharath Institute of Higher education and research, Chennai , India.Email: micgeo270479@gmail.com

Dr.R.Kavitha Department of Computer Science and Engineering, Bharath Institute of Higher education and research, Chennai , India.Email: kavis_happy@yahoo.co.in

Allin Geo Varghese*, Department of Computer Science and Engineering, Bharath Institute of Higher education and research, Chennai , India.Email: seemeallin@gmail.com

\section{A.Existing System}

Asymptotic throughput as a component of and furthermore demonstrate that the asymptotic throughput will be nonzero just if in any event scales with . Be that as it may, they just consider the channel connection model with and utilize a totally distinctive verification system. Also, no unequivocal expression on the asymptotic throughput is given.[14,15,16,17]

\section{B Proposed System}

We consider a telecast station with recipients. Time is opened, and the quantities of show bundle entries over various time-openings are with limited difference. We signify the normal number of parcel landings per space as the bundle entry rate the transmission begins when there are more than bundles holding up in the approaching line proposed for every one of the collectors. Rather than transmitting these bundles in a steady progression utilizing criticism and retransmissions, we see every information parcel as an image and encode the first of them into a subjective number of coded images as required utilizing rateless codes for instance, Raptor codes or arbitrary straight codes ) until the coding square is decoded. These parcels together shape a solitary coding hinder with being called piece size. Amid the transmission, the coded images are transmitted in a steady progression. Every collector sends an ACK criticism signal[2] after it has effectively decoded the parcels. We expect that the ACK sign is transmitted immediately and got without mistake. In the accompanying connection, the terms parcel and image are utilized conversely in Figure:1.[18,19,20,21]

\section{SYSTEM ARCHITECTURE}

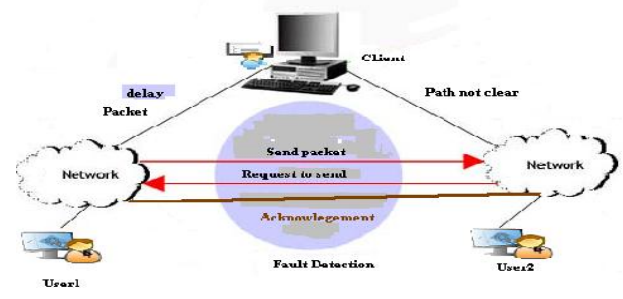

Fig:1 System Architecture

Published By: 


\section{MODULE DESCRIPTION}

\section{A.Data Fragments}

In this telecast system, stations between the transmitter and the recipients are displayed as parcel eradication stations where transmitted bundles may either be deleted or effectively gotten. This model depicts a circumstance where parcels may get lost or are not decodable at the collector because of an assortment of variables, for example, channel blurring, obstruction, or checksum blunders. Crosswise over users, but can be corresponded in time in Fig:2. The best encoding and deciphering unpredictability of rate less codes (e.g., Raptor codes)increase straightly as the coding square size increments. Besides, expanding the coding square size can bring about huge postponements and substantial beneficiary support size.[22,23,24,25]

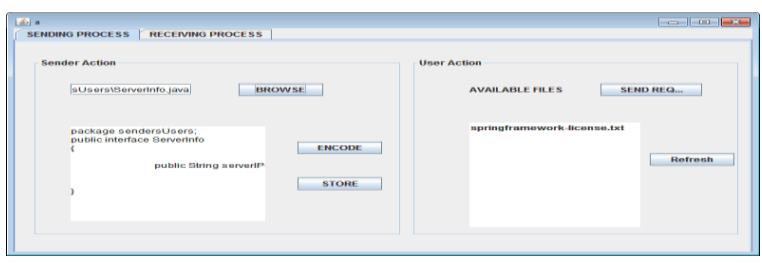

Fig:2 Data Fragments

\section{B. ACK Feedback}

Every recipient sends an ACK[3] input signal after it has effectively decoded the bundles. We accept that the ACK sign in Fig:3 is transmitted quickly and got without mistake. In the accompanying setting, the terms bundle and image are utilized bury variably. We show the telecast station as an opened show bundle eradication station where one parcel can be transmitted associates part. the channel elements are regularly briefly corresponded, we explore the circumstance where the present channel state dissemination relies on upon the direct states in the first run through openings.[26,27,28,29]

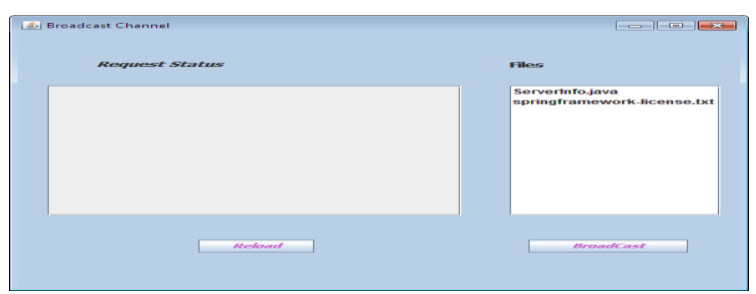

Fig:3 ACK Feedback

\section{C.Data Retransmission}

Rather than transmitting the show information parcel consistently through input and retransmissions, we explores class of coding plans called rate less codes[4] . In this coding plan, show parcels are encoded together before transmission. is known as the coding square size. A rate less encoder sees these bundles as info images and can create a self-assertive number of yield images as required until the coding piece is decoded. The transmission begins when there are more than bundles holding up in the approaching line planned for every one of the recipients in Fig:4. As opposed to transmitting these packages reliably using info and retransmissions.[30,31,32,33]

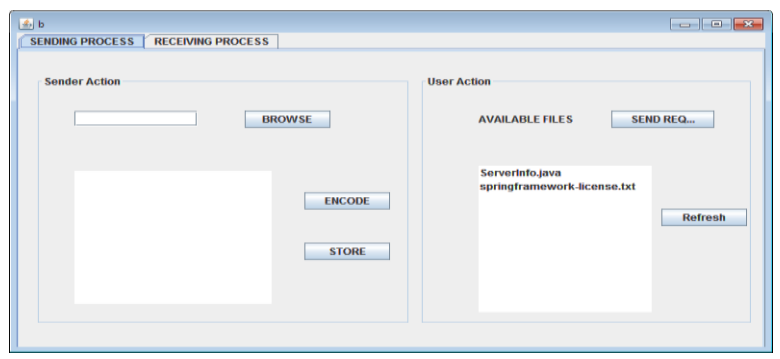

Fig:4 Data Fragments

\section{D.Transmission Time}

A lower bound on the throughput as far as the transmission time of a framework with bigger and when the channels are memoryless, if is kept steady, this lower bound uncovers that the throughput will take after a diminishing example as the quantity of beneficiaries increments in Fig:4. This lower bound uncovers that when develops with in a way that the proportion is kept steady, the throughput takes after a diminishing example as expansions the underlying state and the transmission time of the coding square, separately. At that point, is the aggregate number of state moves that happen in time-openings, this outcome demonstrates that, by keeping the proportion to be a consistent, the framework throughput will focalize to the asymptotic throughput in a diminishing way as n develops[5].

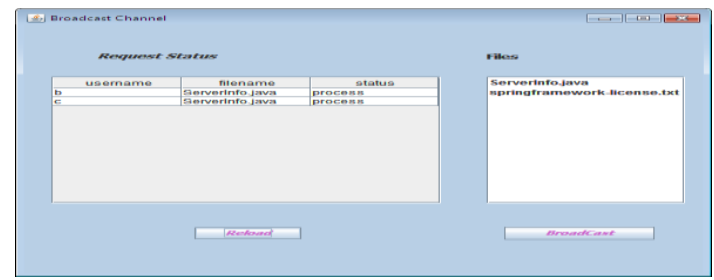

Fig:4 Data Fragments

\section{V.SYSTEM IMPLEMENTATION}

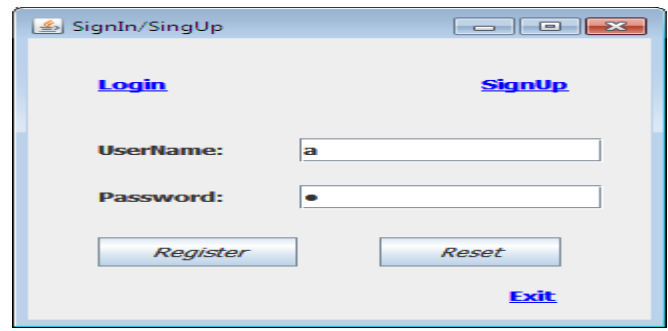

Fig:5

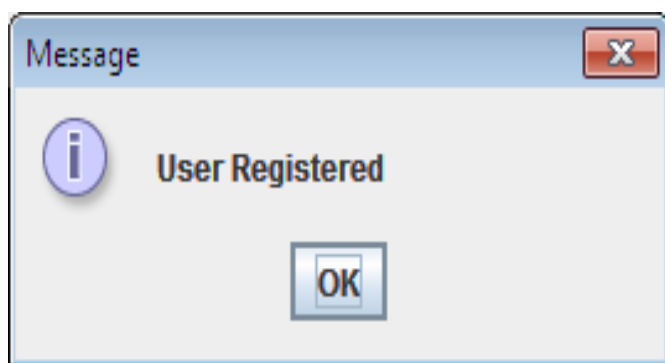

Fig:6 


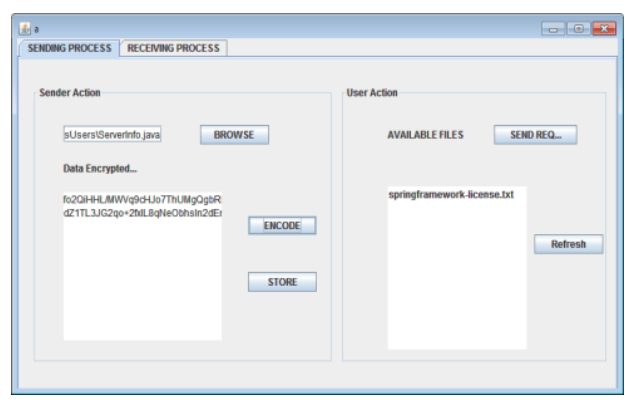

Fig:7

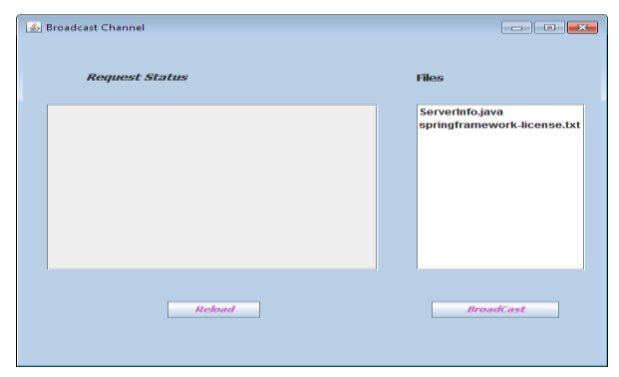

Fig:8

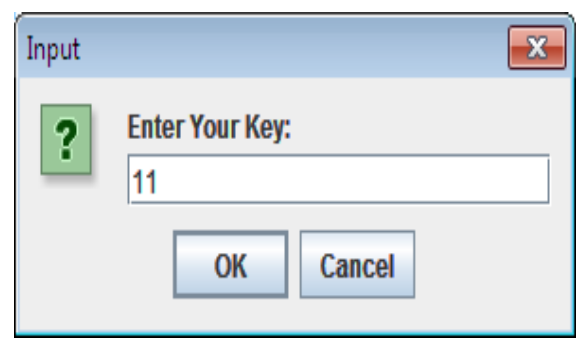

Fig:9

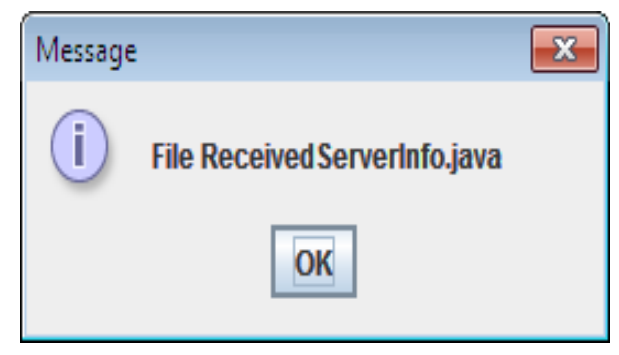

Fig:10

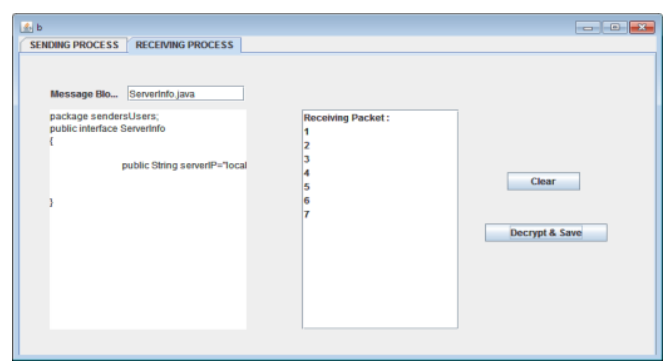

Fig:11

\section{IV.RESULT}

Remote sensor systems[6] are empowering applications that beforehand were not viable. As new standardsbased systems are discharged and low power frameworks are ceaselessly created, we will begin to see the across the board arrangement of remote sensor systems. Sensor hubs can be envisioned as little PCs, to a great degree essential regarding their interfaces and their parts. In software engineering and information transfers, remote sensor systems are a dynamic exploration range with various workshops and gatherings organized every year. [34,35,36,37]

\section{V.CONCLUSION}

Remote sensor systems are empowering applications that beforehand were not handy. As new standards based systems are discharged and low power frameworks are ceaselessly created, we will begin to see the far reaching sending of remote sensor systems. Sensor hubs can be envisioned as little PCs[7], to a great degree essential as far as their interfaces and their parts. In software engineering and information transfers, remote sensor systems are a dynamic examination region with various workshops and meetings orchestrated every year. Every one of this sensor system examination is delivering another innovation which is now showing up in numerous viable applications. The future ought to see a quickened pace of selection of this innovation[8].

\section{VI.FUTURE SCOPE}

In spite of the fact that this anticipate has numerous additional point of interest, in future we get a kick out of the chance to overhaul this into the following level that is not just by simply seeing the caught picture[9], we can likewise see the whole clasp of what happened and what has been caught. This will be done exactly at the unconstrained minute, inside seconds of the activity been happened at the site. $[38,39,40,41]$

\section{REFERENCES}

1] A., Rangarajan K.,Algorithm for automaton specification for exploring dynamic labyrinths,Indian Journal of Science and Technology,V-6,I-SUPPL5,PP-4554-4559,Y-2013

[2] P. Kavitha, S. Prabakaran "A Novel Hybrid Segmentation Method with Particle Swarm Optimization and Fuzzy C-Mean Based On Partitioning the Image for Detecting Lung Cancer" International Journal of Engineering and Advanced Technology (IJEAT) ISSN: 2249-8958, Volume-8 Issue-5, June 2019

[3] Kumaravel A., Meetei O.N.,An application of non-uniform cellular automata for efficient cryptography,2013 IEEE Conference on Information and Communication Technologies, ICT 2013,V-,I-,PP-1200-1205,Y-2013

[4] Kumarave A., Rangarajan K.,Routing alogrithm over semi-regular tessellations,2013 IEEE Conference on Information and Communication Technologies, ICT 2013,V-,I-,PP-1180-1184,Y-2013

[5] P. Kavitha, S. Prabakaran "Designing a Feature Vector for Statistical Texture Analysis of Brain Tumor" International Journal of Engineering and Advanced Technology (IJEAT) ISSN: 2249-8958, Volume-8 Issue-5, June 2019

[6] Dutta P., Kumaravel A.,A novel approach to trust based identification of leaders in social networks,Indian Journal of Science and 
Technology,V-9,I-10,PP--,Y-2016

[7] Kumaravel A., Dutta P.,Application of Pca for context selection for collaborative filtering,Middle - East Journal of Scientific Research,V-20,I-1,PP-88-93,Y-2014

[8] Kumaravel A., Rangarajan K.,Constructing an automaton for exploring dynamic labyrinths,2012 International Conference on Radar, Communication and Computing, ICRCC 2012,V-,I-,PP-161-165,Y-2012

[9] P. Kavitha, S. Prabakaran "Adaptive Bilateral Filter for Multi-Resolution in Brain Tumor Recognition" International Journal of Innovative Technology and Exploring Engineering (IJITEE) ISSN: 2278-3075, Volume-8 Issue-8 June, 2019

[10] Kumaravel A.,Comparison of two multi-classification approaches for detecting network attacks,World Applied Sciences Journal,V-27,I-11,PP-1461-1465,Y-2013

[11] Tariq J., Kumaravel A.,Construction of cellular automata over hexagonal and triangular tessellations for path planning of multi-robots,2016 IEEE International Conference on Computational Intelligence and Computing Research, ICCIC 2016,V-,I-,PP--,Y-2017

[12] Sudha M., Kumaravel A.,Analysis and measurement of wave guides using poisson method,Indonesian Journal of Electrical Engineering and Computer Science,V-8,I-2,PP-546-548,Y-2017

[13] Ayyappan G., Nalini C., Kumaravel A.,Various approaches of knowledge transfer in academic social network,International Journal of Engineering and Technology,V-,I-,PP-2791-2794,Y-2017

[14] Kaliyamurthie, K.P., Sivaraman, K., Ramesh, S. Imposing patient data privacy in wireless medical sensor networks through homomorphic cryptosystems 2016, Journal of Chemical and Pharmaceutical Sciences 92.

[15] Kaliyamurthie, K.P., Balasubramanian, P.C. An approach to multi secure to historical malformed documents using integer ripple transfiguration 2016 Journal of Chemical and Pharmaceutical Sciences 92

[16] A.Sangeetha,C.Nalini,"Semantic Ranking based on keywords extractions in the web", International Journal of Engineering \& Technology, 7 (2.6) (2018) 290-292

[17] S.V.GayathiriDevi,C.Nalini,N.Kumar,"An efficient software verification using multi-layered software verification tool "International Journal of Engineering \& Technology, 7(2.21)2018 454-457

[18] C.Nalini,ShwtambariKharabe,"A Comparative Study On Different Techniques Used For Finger - Vein Authentication", International Journal Of Pure And Applied Mathematics, Volume 116 No. 82017 , 327-333, Issn: 1314-3395

[19] M.S. Vivekanandan and Dr. C. Rajabhushanam, "Enabling Privacy Protection and Content Assurance in Geo-Social Networks", International Journal of Innovative Research in Management, Engineering and Technology, Vol 3, Issue 4, pp. 49-55, April 2018.

[20] Dr. C. Rajabhushanam, V. Karthik, and G. Vivek, "Elasticity in Cloud Computing", International Journal of Innovative Research in Management, Engineering and Technology, Vol 3, Issue 4, pp. 104-111, April 2018.

[21] K. Rangaswamy and Dr. C. Rajabhushanamc, "CCN-Based Congestion Control Mechanism In Dynamic Networks", International Journal of Innovative Research in Management, Engineering and Technology, Vol 3, Issue 4, pp. 117-119, April 2018.

[22] Kavitha, R., Nedunchelian, R., "Domain-specific Search engine optimization using healthcare ontology and a neural network backpropagation approach", 2017, Research Journal of Biotechnology, Special Issue 2:157-166

[23] Kavitha, G., Kavitha, R., "An analysis to improve throughput of high-power hubs in mobile ad hoc network" , 2016, Journal of Chemical and Pharmaceutical Sciences, Vol-9, Issue-2: 361-363

[24] Kavitha, G., Kavitha, R., "Dipping interference to supplement throughput in MANET" , 2016, Journal of Chemical and Pharmaceutical Sciences, Vol-9, Issue-2: 357-360

[25] Michael, G., Chandrasekar, A.,'Leader election based malicious detection and response system in MANET using mechanism design approach", Journal of Chemical and Pharmaceutical Sciences(JCPS) Volume 9 Issue 2, April - June 2016

[26] Michael, G., Chandrasekar, A.,"Modeling of detection of camouflaging worm using epidemic dynamic model and power spectral density", Journal of Chemical and Pharmaceutical Sciences(JCPS) Volume 9 Issue 2, April - June 2016

[27] Pothumani, S., Sriram, M., Sridhar, J., Arul Selvan, G., Secure mobile agents communication on intranet,Journal of Chemical and Pharmaceutical Sciences, volume 9, Issue 3, Pg No S32-S35, 2016

[28] Pothumani, S., Sriram, M., Sridhar , Various schemes for database encryption-a survey, Journal of Chemical and Pharmaceutical Sciences, volume 9, Issue 3, Pg NoS103-S106, 2016

[29] Pothumani, S., Sriram, M., Sridhar, A novel economic framework for cloud and grid computing, Journal of Chemical and Pharmaceutical Sciences, volume 9, Issue 3, Pg No S29-S31, 2016

[30] Priya, N., Sridhar, J., Sriram, M. "Ecommerce Transaction Security Challenges and Prevention Methods- New Approach” 2016 ,Journal of Chemical and Pharmaceutical Sciences, JCPS Volume 9 Issue 3.page no:S66-S68 .

[31] Priya, N.,Sridhar,J.,Sriram, M."Vehicular cloud computing security issues and solutions" Journal of Chemical and Pharmaceutical Sciences(JCPS) Volume 9 Issue 2, April - June 2016

[32]

[33] Priya, N., Sridhar, J., Sriram, M. "Mobile large data storage security in cloud computing environment-a new approach" JCPS Volume 9 Issue 2. April - June 2016

[34] Anuradha.C, Khanna.V, "Improving network performance and security in WSN using decentralized hypothesis testing "Journal of Chemical and Pharmaceutical Sciences(JCPS) Volume 9 Issue 2, April - June 2016.

[35] Anuradha.C, Khanna.V, "A novel gsm based control for e-devices" Journal of Chemical and Pharmaceutical Sciences(JCPS) Volume 9 Issue 2, April - June 2016

[36] Anuradha.C, Khanna.V, "Secured privacy preserving sharing and data integration in mobile web environments " Journal of Chemical and Pharmaceutical Sciences(JCPS) Volume 9 Issue 2, April - June 2016.

[37] Sundarraj, B., Kaliyamurthie, K.P. Social network analysis for decisive the ultimate classification from the ensemble to boost accuracy rates

2016 International Journal of Pharmacy and Technology 8

[38] Sundarraj, B., Kaliyamurthie, K.P. A content-based spam filtering approach victimisation artificial neural networks 2016 International Journal of Pharmacy and Technology 83 .

[39] Sundarraj, B., Kaliyamurthie, K.P. Remote sensing imaging for satellite image segmentation 2016 International Journal of Pharmacy and Technology 83 .

[40] Sivaraman, K., Senthil, M. Intuitive driver proxy control using artificial intelligence 2016 International Journal of Pharmacy and Technology $8 \quad 4$.

[41] Sivaraman, K., Kaliyamurthie, K.P. Cloud computing in mobile technology 2016 Journal of Chemical and Pharmaceutical Sciences 92.

[42] Sivaraman, K., Khanna, V. Implementation of an extension for browser to detect vulnerable elements on web pages and avoid click jacking 2016 Journal of Chemical and Pharmaceutical Sciences 92.

\section{AUTHORS PROFILE}

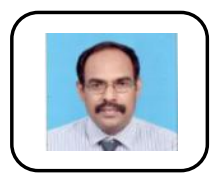

G. Michael, Associate Professor, Department of Computer Science \& Engineering, Bharath Institute of Higher Education and Research, Chennai, India

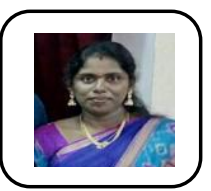

Dr. R.Kavitha, Associate Professor, Department of Computer Science \& Engineering, Bharath Institute of Higher Education and Research, Chennai, India

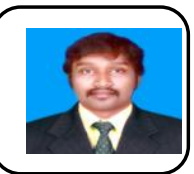

Allin Geo Varghese , Associate Professor, Department of Computer Science \& Engineering, Bharath Institute of Higher Education and Research, Chennai, India 